\title{
A peeling DEA-game cross efficiency procedure to classify suppliers
}

\author{
Corrado lo Storto* \\ ${ }^{1}$ University of Naples Federico II, Department of Industrial Engineering, Piazzale V. Tecchio 80, \\ 80125 Naples, Italy
}

\begin{abstract}
This paper proposes a non-parametric procedure to classify suppliers. The procedure adopts a peeling approach and Data Envelopment Analysis-game cross efficiency (DEA-GXE) method to group a set of suppliers into classes. In DEA-GXE each supplier is seen as a player competing in an uncooperative environment, seeking to maximize efficiency under the condition that the other suppliers'cross-efficiency does not deteriorate. The procedure is useful when there is a long list of suppliers that should be assessed by the customer, providing an agile decision-making tool.
\end{abstract}

\section{Introduction}

Supplier assessment and classification is an important step of the purchasing decision-making process in a manufacturing company. Selecting high quality suppliers provides competitive advantage with the management of the supply chain. Choosing good suppliers as partners along the supply chain contributes to reducing operational costs, improving process and product quality. A number of scholars focused on the supplier selection problem, i.e. the analysis and measurement of the performance of a set of suppliers in order to generate a relative rank and select one or more of them. Literature includes a large number of approaches and models that are based on multi-objective optimization (MOP) [1,2], analytic hierarchical process (AHP) [3,4], simple multi-attribute rating techniques (SMART) [5], and data envelopment analysis (DEA) [6,7]. However, even though they provide systematic frameworks that purchasing managers can utilize, most of them are not easily implementable and imply a large amount of subjectivity to weight individual criteria. Vice versa, frameworks based on DEA are more effective to reduce the evaluators' subjectivity as weights are endogenously determined from data and no assumptions relative to relationships among variables are necessary.

This paper proposes a non-parametric DEA based procedure to classify suppliers. The procedure adopts DEA-game cross efficiency (DEA-GXE) method to rank a dataset of suppliers and a peeling procedure to group them into classes. In DEA-GXE every supplier to be ranked is seen as a player competing in an uncooperative environment, seeking to maximize efficiency under the condition that the cross-efficiency scores of the other suppliers do not deteriorate. The procedure is particularly useful when there is a large number of

\footnotetext{
*Corresponding author: corrado.lostorto@unina.it
} 
suppliers that should be preliminarily assessed by the customer and classified, providing an agile decision-making tool. The paper is organized as follows. Section 2 describes the DEAGXE method and the peeling procedure. Section 3 reports the result of the implementation of the method. Finally, section 4 presents some concluding remarks.

\section{Method}

\subsection{Supplier classification procedure}

The procedure to classify suppliers implements DEA game-cross efficiency (DEA-GXE) to generate efficiency measurements relative to suppliers and the DEA peeling approach to classify them into different classes.

\subsection{DEA game-cross efficiency}

DEA is a non-parametric linear programming based technique that calculates the relative efficiencies of a number of decision making units denominated DMUs. The efficient units are identified from this set and combined together to construct an efficient frontier used as a benchmark to measure the efficiency of inefficient units [8].

In the proposed approach, each DMU is an individual supplier $S_{i}$ in the dataset that can be associated to a specific production function producing $\boldsymbol{Y}=\left(x_{i j}\right) \in \mathfrak{R} \mathfrak{R}^{\mathrm{s} \times n}$ outputs by combining $X=\left(x_{i j}\right) \in \mathfrak{R}^{m \times n}$ inputs. The DMU ability to produce a given amount of outputs with the minimum consumption of inputs or the maximum amount of outputs by consuming the same amount of input independently of any input and output price set is referred to as technical efficiency (TE).

The original model proposed by [9] classifies units into two groups, e.g. the efficient (scoring $\mathrm{TE}=100 \%$ ) and the inefficient units (scoring $\mathrm{TE}<100 \%$ ) and provides a relative rank for these latter only, having a weak discriminating power. Scholars have proposed different approaches and methods to improve the discriminating capability of DEA and generate full rankings among alternatives $[10,11]$. The approach based on the calculation of the crossefficiency scores of DMUs is effective to improve the discriminating capability of DEA and does not need introducing any subjectivity in the ranking procedure as a consequence of weighting schemes provided by expert judgment $[12,13]$.

Assume that there are $n$ DMUs and every DMU $j(j=1, \ldots, n)$ produces $s$ outputs $y_{r j}$ $(r=1, \ldots, s)$ consuming $m$ inputs $x_{i j}(i=1, \ldots, m)$. The cross-efficiency of each DMU $j, \theta_{k j}$, can be easily calculated using the optimal values of weights computed for DMU $k, \omega_{r k}$ and $\mu_{i k}$, as follows

$$
\theta_{k j}=\frac{\sum_{r=1}^{s} \omega_{r k}^{*} y_{r j}}{\sum_{i=1}^{m} \mu_{i k}^{*} x_{i j}} \quad j \neq k \text { and } j=1, \ldots, n
$$

The DMUs cross-efficiencies are calculated in two steps. First, by solving model (2) $n$ times basic DEA is performed to calculate the optimal weights assigned to DMU inputs and outputs as suggested by [9]. Here an input orientation and constant returns to scale are assumed. 


$$
\begin{array}{ll}
\operatorname{Max} & \sum_{r=1}^{s} \omega_{r k} y_{r k} \\
\text { s.t. } & \sum_{i=1}^{m} \mu_{i k} x_{i k}=1 \\
& \sum_{r=1}^{s} \omega_{r k} y_{r j}-\sum_{i=1}^{m} \mu_{i k} x_{i j} \leq 0 \quad j=1, \ldots, n \\
& \omega_{r k} \geq 0, \mu_{i k} \geq 0, \quad r=1, \ldots, s \text { and } i=1, \ldots, m
\end{array}
$$

Second, the $n \times n$ cross-efficiencies matrix of DMUs is generated. In the matrix, the offdiagonal entries show the cross-efficiencies, while the diagonal entries are the basic DEA efficiency scores. Finally, for each DMU $k$, cross-efficiencies are aggregated to obtain a mean cross-efficiency measurement.

Liang et al. [14] have proposed a DEA game cross-efficiency measurement. In DEA game, the DMU cross-efficiency is measured as the pay-off of a non-cooperative game that the DMU aims at maximizing. Scholars also suggested a robust iterative algorithm to generate the best average game cross-efficiency measurements, and proved that the suggested algorithm originates a set of unique Nash equilibrium DEA weights. In order to calculate the cross-efficiency of DMU $k$ related to DMU $j$, a set of weights is found to maximize the efficiency of DMU $k$ with the additional restriction that the efficiency of DMU $j$ does not diminish. The efficiencies of the other DMUs should be known to calculate the efficiency of each DMU, and vice versa.

The cross-efficiency of DMU $k$ related to $\mathrm{DMU} j$ is denoted as

$$
\alpha_{k j}=\frac{\sum_{r=1}^{s} \omega_{r j}^{k} y_{r j}}{\sum_{i=1}^{m} \mu_{i j}^{k} x_{i j}} \quad k=1, \ldots, n
$$

where $\omega^{k}{ }_{r j}$ and $\mu^{k}$ ar optimal weights. The following linear programming model (4) is utilized to implement the proposed procedure $[14,15]$

$$
\begin{array}{lll}
\operatorname{Max} & \sum_{r=1}^{s} \omega_{r j}^{k} y_{r j} & \\
\text { s.t. } & \sum_{i=1}^{m} \mu_{i j}^{k} x_{i l}-\sum_{r=1}^{s} \omega_{r j}^{k} y_{r l} \geq 0 & l=1, \ldots, n \\
& \alpha_{k} \times \sum_{i=1}^{m} \mu_{i j}^{k} x_{i k}-\sum_{r=1}^{s} \omega_{r j}^{k} y_{r k} \leq 0 & j=1, \ldots, n \\
& \sum_{i=1}^{m} \mu_{i j}^{k} x_{i j}=1 & j=1, \ldots, n \\
& \omega_{r j}^{k} \geq 0, \mu_{i j}^{k} \geq 0, r=1, \ldots, s \text { and } & i=1, \ldots, m \\
& \alpha_{k} \leq 1 &
\end{array}
$$

\subsection{The peeling approach}

The idea of "peeling the DEA onion" was firstly suggested by [16]. In the peeling approach, DEA is applied to variable datasets that are extracted from the main dataset at different steps [17]. In the first step, DEA is applied to the whole dataset to find efficient DMUs. At this step, efficient DMUs compose the first layer and accordingly are classified in the first class. Efficient DMUs are removed from the whole dataset and a smaller dataset is extracted from the first one, including only previously inefficient DMUs.

In the second step, DEA is applied to the reduced dataset and DMUs resulting efficient compose the second layer, assigned to the second class, and finally removed from the dataset 
to move to the next step. This process continues until all the DMUs in the dataset have been assigned to a layer.

\section{Example}

The dataset for this example is taken from [18]. It contains data relative to 23 suppliers which are assessed according to 11 attributes, respectively clustered into 6 inputs and 5 outputs (see Table 1).

Table 1. Original inputs and outputs.

\begin{tabular}{|c|c|c|c|}
\hline \multicolumn{2}{|c|}{ inputs } & \multicolumn{2}{c|}{ ouputs } \\
\hline variable & attribute & variable & attribute \\
\hline $\mathrm{QMP}(\mathrm{X} 1)$ & quality management practices and & QUALITY(Y1) & quality \\
\hline $\mathrm{SA}(\mathrm{X} 2)$ & documentation and self audit & PRICE(Y2) & price \\
\hline $\mathrm{PMC}(\mathrm{X} 3)$ & process and manufacturing capability & DELIVERY(Y3) & delivery \\
\hline $\mathrm{MF}(\mathrm{X} 4)$ & management of the firm & $\mathrm{CRP}(\mathrm{Y} 4)$ & $\begin{array}{c}\text { cost reduction } \\
\text { performance }\end{array}$ \\
\hline $\mathrm{DD}(\mathrm{X} 5)$ & design and development capabilities & OTHER(Y5) & other \\
\hline $\mathrm{CR}(\mathrm{X} 6)$ & cost reduction capabilities & & \\
\hline
\end{tabular}

To meet the strictly positivity requirement of DEA, zero values were preliminarily eliminated by adding a constant scalar equal to 0.05 to all measurements. Additionally, because of the large number of input and output variables, in order to increase DEA discriminating capability, Principal Component Analysis (PCA) was used to reduce the dataset dimensionality. After running PCA, variables were reduced to 2 inputs and 2 outputs whose measurements were generated as weighted averages of original measurements using PCA factor loadings as weights. The new set of inputs and outputs considered for the subsequent analysis are showed in Table 2.

Table 2. Inputs and outputs used in the analysis.

\begin{tabular}{|c|c|}
\hline new inputs and outputs & original inputs and outputs \\
\hline $\mathrm{I}_{1}$ & $\mathrm{QMP}(\mathrm{X} 1), \mathrm{PMC}(\mathrm{X} 3), \mathrm{MF}(\mathrm{X} 4), \mathrm{DD}(\mathrm{X} 5), \mathrm{CR}(\mathrm{X} 6)$ \\
\hline $\mathrm{I}_{2}$ & $\mathrm{SA}(\mathrm{X} 2)$ \\
\hline $\mathrm{O}_{1}$ & $\mathrm{QUALITY}(\mathrm{Y} 1), \mathrm{DELIVERY}(\mathrm{Y} 3), \mathrm{OTHER}(\mathrm{Y} 5)$ \\
\hline $\mathrm{O}_{2}$ & $\mathrm{PRICE}(\mathrm{Y} 2), \mathrm{CRP}(\mathrm{Y} 4)$ \\
\hline
\end{tabular}

Table 3 reports the output of the implementation of the classification procedure. Without loss of generalizability, the procedure was stopped after the generation of the first 4 layers (layer $0, \ldots$,layer 3 ) and aggregation of suppliers in 4 classes $(1, \ldots, 4)$. Particularly, table provides information relative to the game cross-efficiency score, rank for every layers, and suppliers excluded from the dataset at each step. In the first step, only one supplier was evaluated as $100 \%$ efficient. In the second step, the DEA game cross-efficiency algorithm did not identify any $100 \%$ supplier. Differently from conventional DEA, the best crossefficiency score may be less than 1 because it is finally calculated as the mean value of different efficiencies. Thus, as a decision-making rule adopted in this example, suppliers scoring more than 0.95 were excluded from the dataset to move to the next step. In the same way, layers 2 and 3 were generated by excluding the 100\% efficient suppliers. 
Table 4 displays how suppliers have been classified. Class 1 contains one supplier only (S22), class 2 contains five suppliers (S4, S6, S7, S15, and S23), class 3 includes one supplier (S20), and finally class 4 includes one supplier (S12).

Table 3. Results (first 4 layers).

\begin{tabular}{|c|c|c|c|c|c|c|c|c|}
\hline \multirow{2}{*}{ Supplier } & \multicolumn{2}{|c|}{ Layer 0 } & \multicolumn{2}{c|}{ Layer 1 } & \multicolumn{2}{c|}{ Layer 2 } & \multicolumn{2}{c|}{ Layer 3 } \\
\cline { 2 - 9 } & DEA-GXE & rank & DEA-GXE & rank & DEA-GXE & rank & DEA-GXE & rank \\
\hline S1 & 0.463 & 19 & 0.464 & 18 & 0.660 & 11 & 0.661 & 11 \\
\hline S2 & 0.378 & 21 & 0.370 & 20 & 0.527 & 14 & 0.534 & 14 \\
\hline S3 & 0.862 & 8 & 0.857 & 7 & 0.962 & 4 & 0.982 & 3 \\
\hline S4 & 0.981 & 3 & 0.998 & 1 & - & - & - & - \\
\hline S5 & 0.676 & 11 & 0.707 & 10 & 0.912 & 5 & 0.922 & 4 \\
\hline S6 & 0.945 & 6 & 0.971 & 5 & - & - & - & - \\
\hline S7 & 0.958 & 4 & 0.986 & 3 & - & - & - & - \\
\hline S8 & 0.564 & 15 & 0.581 & 15 & 0.779 & 8 & 0.786 & 7 \\
\hline S9 & 0.333 & 22 & 0.345 & 21 & 0.435 & 16 & 0.445 & 15 \\
\hline S10 & 0.886 & 7 & 0.864 & 6 & 0.971 & 3 & 0.989 & 2 \\
\hline S11 & 0.576 & 14 & 0.589 & 13 & 0.727 & 10 & 0.743 & 9 \\
\hline S12 & 0.736 & 10 & 0.761 & 9 & 0.998 & 2 & 1.000 & 1 \\
\hline S13 & 0.606 & 12 & 0.633 & 11 & 0.817 & 6 & 0.826 & 5 \\
\hline S14 & 0.562 & 16 & 0.589 & 14 & 0.758 & 9 & 0.768 & 8 \\
\hline S15 & 0.985 & 2 & 0.988 & 2 & - & - & - & - \\
\hline S16 & 0.411 & 20 & 0.419 & 19 & 0.525 & 15 & 0.540 & 13 \\
\hline S17 & 0.483 & 18 & 0.495 & 17 & 0.607 & 13 & 0.620 & 12 \\
\hline S18 & 0.316 & 23 & 0.320 & 22 & 0.373 & 17 & 0.380 & 16 \\
\hline S19 & 0.589 & 13 & 0.612 & 12 & 0.797 & 7 & 0.809 & 6 \\
\hline S20 & 0.775 & 9 & 0.796 & 8 & 1.000 & 1 & - & - \\
\hline S21 & 0.530 & 17 & 0.541 & 16 & 0.656 & 12 & 0.669 & 10 \\
\hline S22 & 1.000 & 1 & - & - & - & - & & - \\
\hline S23 & 0.947 & 5 & 0.976 & 4 & - & - & & - \\
\hline
\end{tabular}

Table 4. Classified suppliers (first 4 classes).

\begin{tabular}{|c|c|c|c|c|c|}
\hline Class & \multicolumn{5}{|c|}{ Classified Suppliers } \\
\hline class 1 & $\begin{array}{c}\text { S22 } \\
(1.000)\end{array}$ & & & & \\
\hline class 2 & $\begin{array}{c}\text { S4 } \\
(0.998)\end{array}$ & $\begin{array}{c}\text { S6 } \\
(0.971)\end{array}$ & $\begin{array}{c}\text { S7 } \\
(0.986)\end{array}$ & $\begin{array}{c}\text { S15 } \\
(0.988)\end{array}$ & $\begin{array}{c}\text { S23 } \\
(0.976)\end{array}$ \\
\hline class 3 & $\begin{array}{c}\text { S20 } \\
(1.000)\end{array}$ & & & & \\
\hline class 4 & $\begin{array}{c}\text { S12 } \\
(1.000)\end{array}$ & & & & \\
\hline$\ldots$ & $\ldots$ & $\ldots$ & $\ldots$ & $\ldots$ & $\ldots$ \\
\hline class $\mathrm{j}$ & $\ldots$ & $\ldots$ & $\ldots$ & $\ldots$ & $\ldots$ \\
\hline
\end{tabular}

\section{Conclusion}

This paper has presented a computational procedure to classify suppliers. The procedure is based on the implementation of DEA game cross-efficiency (DEA-GXE) and a peeling approach to associate suppliers to classes. While DEA-GXE is considered an effective procedure to generate rankings, a difference in the ranking position of suppliers may be due to small differences of their efficiency scores (i.e., the third or even the fourth digit). Thus, the resulting ranking can be rather aleatory because of measurement uncertainty, implemented algorithm, and numerical approximation. Combining both DEA-GXE and the peeling procedure allows having a more robust and refined classification than using only the 
classical peeling approach as suggested by [16]. The innovative procedure has been applied to classify a dataset of 23 suppliers. Results indicate that the proposed procedure can be easily implemented and is effective to generate classes of suppliers. Additionally, given its flexibility, it can be adapted to context by modifying exclusion and selection rules.

\section{References}

1. S. Deng, R. Aydin, C.K. Kwong, Yun Huang, Comput. Ind Eng., 70, 150 (2014)

2. R. Narasimhan, S. Talluri, S.K. Mahapatra, Decision Sci., 37, 577 (2006)

3. F.T.S. Chan, Int. J. Prod. Res. 41, 3549 (2003)

4. V. Yadav, M.K. Sharma, Journal of Modelling in Management, 11, 326 (2016)

5. S.H. Huang, H. Keska, Int. J. Prod. Econ., 105, 510 (2007)

6. R.C. Baker, S. Talluri, Comput. Ind. Eng. 32, 101 (1997)

7. J. Seydel, Ind. Manage. Data. Syst., 106, 81 (2006)

8. W.W. Cooper, L.M. Seiford, K. Tone, Data Envelopment Analysis: A Comprehensive Text with Models, Applications, References and DEA-Solver Software, (2nd Ed. Springer-Verlag, Berlin, Germany, 2006)

9. A. Charnes, W.W. Cooper, E. Rhodes, Eur. J. Oper. Res., 2, 429 (1978)

10. N. Adler, L. Friedman, Z. Sinuany-Stern, Eur. J. Oper. Res., 140, 249 (2002)

11. L.A. Meza, M.P.E. Lins, Ann. Oper. Res., 116, 225 (2002)

12. J.R. Doyle, R.H. Green, J. Oper. Res. Soc., 45, 567 (1994)

13. C. lo Storto, Sustainability, 8, 124 (2016)

14. L. Liang, J. Wu, W.D. Cook, J. Zhu, Oper. Res., 56, 1278 (2008)

15. J. Wu, L. Liang, Y. Chen, Omega, 37, 909 (2009)

16. R.S. Barr, M.L. Durchholz, L. Seiford, Southern Methodist University Technical Report, 5, 1 (1994)

17. M. Bougnol, J. Dul'a, Ann. Oper. Res., 145, 339 (2006)

18. R. Narasimhan, S. Talluri, D. Mendez, The Journal of Supply Chain Management: A Global Review of Purchasing and Supply, Summer, 28 (2001) 